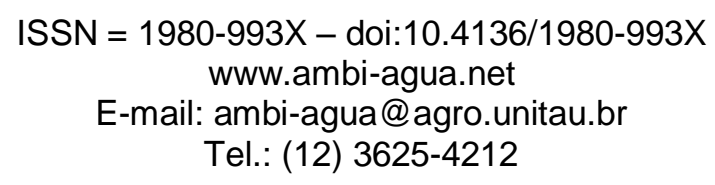

\title{
Adequação de um protocolo de avaliação rápida de rios para ser usado por estudantes do ensino fundamental
}

\author{
(http://dx.doi.org/10.4136/ambi-agua.996)
}

\author{
Ariane Guimarães ${ }^{1}$; Aline Sueli de Lima Rodrigues²; Guilherme Malafaia ${ }^{3}$ \\ ${ }^{1}$ Bolsista do Programa Institucional de Bolsas de Iniciação Científica do CNPq, \\ Curso de Ciências Biológicas /Licenciatura, Instituto Federal Goiano - Câmpus Urutaí, Urutaí, GO, \\ e-mail: arianeguimaraeslima@ hotmail.com, \\ ${ }^{2}$ Departamento de Gestão Ambiental, Instituto Federal Goiano - Câmpus Urutaí, Urutaí, GO, \\ Pesquisadora do Núcleo de Pesquisa em Ciências Ambientais e Biológicas, \\ e-mail: rodriguesasl@yahoo.com.br, \\ ${ }^{3}$ Departamento de Ciências Biológicas do Instituto Federal Goiano - Câmpus Urutaí, GO, \\ Pesquisador do Núcleo de Pesquisa em Ciências Ambientais e Biológicas, \\ e-mail: guilhermeifgoiano@gmail.com
}

\section{RESUMO}

O presente estudo teve como objetivo adequar um protocolo de avaliação rápida de rios (PAR) para utilização por crianças do ensino fundamental. O estudo foi desenvolvido em Ipameri, GO e o PAR foi adequado para avaliação de riachos do bioma Cerrado do Sudeste goiano. A partir de dois protocolos referência (um nacional e outro oriundo dos EUA), o PAR adequado abrangeu: parâmetros físicos que condicionam o funcionamento dos riachos, linguagem adaptada ao nível de escolaridade do ensino fundamental e a presença de ilustrações esquemáticas que auxiliam a aplicação do PAR em campo pelos estudantes. Para a consolidação do instrumento desenvolvido, foi oferecida uma oficina de monitoramento a 95 estudantes de duas instituições públicas de ensino e realizada uma análise e interpretação do padrão de respostas obtidas na etapa prática da oficina. Os testes Bartlett e Levene não revelaram diferenças estatísticas entre o padrão de resposta dos estudantes, possibilitando inferir que o PAR desenvolvido mostra-se compreensível por parte dos avaliadores. A aplicação do PAR foi rápida (entre 20 e 40 minutos) e os alunos relataram que o instrumento desenvolvido os aproxima das questões ambientais, que a oficina de monitoramento os ajudou a compreender o instrumento e que as ilustrações disponíveis facilitaram a avalição em campo. Em adição, os estudantes afirmaram que se sentiram sensibilizados para com as questões ligadas à preservação dos recursos hídricos e disseram que a participação na oficina de monitoramento ambiental permitiu a apropriação de conhecimentos sobre o funcionamento dos sistemas fluviais. Conclui-se que o PAR adequado mostra-se como uma ferramenta útil e interessante para ser utilizada em projetos e programas de Educação Ambiental.

Palavras-chave: avaliação ambiental; educação ambiental; aspectos físicos; estudantes.

\section{Adapting a rapid river assessment protocols to be used by elementary school children}

\section{ABSTRACT}

The present study aimed to adapt a rapid river assessment protocols (RAP) to be used by elementary school children. The study was conducted in Ipameri, GO and the RAP was 
adapted for the evaluation of streams in the Cerrado biome. Based on two protocol models, the developed RAP included: physical parameters that affect the functioning of streams, language adapted to the educational level of elementary school and the presence of drawings that could facilitate the field application of RAP by the students. For consolidation of the adapted instrument, it was offered a monitoring workshop to 95 students from two public education institutions, and developed an analysis and interpretation of the pattern of responses obtained during the practical step of the workshop. The Bartlett and Levene tests revealed no statistical differences between the response patterns of the students, allowing to infer that the developed RAP was understandable by the evaluators. The application of the RAP was fast (20 to 40 minutes) and the students reported that the developed instrument helped them to familiarize with environmental issues. In addition, the monitoring workshop helped them to understand the instrument and the available illustrations facilitated the field evaluation. In addition, the students concluded that they have become aware of the issues related to the water resource preservation and also that participation in the environmental monitoring workshop allowed the appropriation of knowledge about the river system functioning. It was concluded that adapted RAP has been proved to be a useful and interesting tool for using in environmental education projects and programs.

Keywords: environmental assessment, environmental education, physic aspects, students.

\section{INTRODUÇÃO}

Nos últimos anos a Educação Ambiental (EA) tem possibilitado cada vez mais a difusão da problemática ambiental e a promoção de práticas conservacionistas (Palhares et al., 2000). Porém, a expansão e as modificações dos processos produtivos, o crescimento populacional, a ocupação de variados nichos ecológicos, as migrações e urbanizações descontroladas, têm desestabilizado as condições de equilíbrio dos recursos naturais, dentre eles a água.

Sobre os recursos hídricos, conforme discutido por Krupek (2010), o ritmo de estudos desenvolvidos não segue a mesma velocidade de sua degradação. Levantamentos minuciosos acerca dos impactos das atividades humanas sobre o funcionamento dos ecossistemas aquáticos são necessários e importantes, porém difíceis ou até mesmo impossíveis de serem realizados quando os recursos financeiros são escassos, quando são feitos em áreas de difícil acesso e quando o tempo disponível é pequeno, o que não significa que não devam ser desenvolvidos.

Em função disso, a preocupação com o estado de degradação dos recursos hídricos tem revelado a necessidade de se estabelecer métodos de avaliação rápida de sua qualidade ambiental. Nesse contexto, uma ferramenta possível de ser utilizada como ferramenta complementar no monitoramento dos recursos hídricos, são os Protocolos de Avaliação Rápida de Rios (PARs), os quais têm a proposta de avaliar, de forma integrada, parâmetros que determinam a qualidade dos condicionantes físicos dos rios (Rodrigues e Castro, 2008a). O uso dos PARs de forma complementar a outras análises da qualidade do recurso fluvial (como análises físico-químicas e microbiológicas da água e do solo, por exemplo), com a devida cautela quando da interpretação dos resultados, permite a obtenção de informações que possibilitem o planejamento do uso e conservação dos recursos fluviais (Rodrigues e Castro, 2008a; Rodrigues et al., 2010).

Por definição, os PARs são ferramentas que reúnem procedimentos metodológicos aplicáveis à avaliação rápida, qualitativa e semi-quantitativa, de um conjunto de variáveis representativas dos principais componentes e fatores que condicionam e controlam os processos e funções ecológicas dos sistemas fluviais (Callisto et al., 2002; Rodrigues e Castro, 2008a). Nos PARs é estabelecido, em princípio, um limite considerado normal baseado em 
valores obtidos de locais minimamente perturbados, tidos como locais "referência" (Plafkin et al., 1989), partindo da premissa de que os cursos d'água pouco afetados pela ação humana exibem melhores condições biológicas (Minatti-Ferreira e Beaumord, 2006). O gradiente de estresse ambiental é definido a partir da observação destes locais e de locais com vários graus de alterações, desde os pouco alterados até os muito degradados.

No Brasil, vários estudos têm utilizado os PARs como instrumentos de avaliação da estrutura física e do funcionamento dos ecossistemas fluviais, como pode ser observado nos trabalhos de Minatti-Ferreira e Beaumord (2004, 2006), Xavier e Teixeira (2007), Dillenburg (2007), Rodrigues et al. (2008), Bergmann e Pedrozo (2008), Pimenta et al. (2009), PadovesiFonseca et al. (2010), Krupek (2010), Firmino et al. (2011), Lobo et al. (2011), Vargas e Ferreira Júnior (2012), Rodrigues et al. (2012), dentre outros.

Uma maneira de tornar esses instrumentos ainda mais úteis seria a adequação dos mesmos para fins de utilização em atividades educativas ligadas à preservação dos ambientes fluviais, conforme realizado por Bergmann e Pedrozo (2008), França et al. (2010), Callisto et al. (2010) e Carvalho (2010). Apesar da existência de estudos com essa vertente, pode-se dizer que poucos pesquisadores envolvidos com a problemática ambiental produzem e analisam materiais educativos para a população com baixo grau de instrução/escolarização, especialmente para crianças em escolarização básica (Bizerril e Faria, 2003).

$\mathrm{Na}$ literatura especializada, apenas um estudo envolvendo PARs e estudantes do ensino fundamental foram encontrados, o qual se refere ao trabalho de Guimarães et al. (2006), desenvolvido no âmbito do projeto ambiental Pampulha Limpa, criado em 2003, em Belo Horizonte, MG. Nesse estudo os autores trabalharam com a aplicação de um PAR por centenas de crianças com idade entre 11 e 13 anos de escolas localizadas na bacia hidrográfica da Pampulha. Na ocasião, foram realizadas saídas de campo para locais que apresentavam condições ambientais distintas e o PAR adequado foi aplicado pelas crianças. Desde então, o protocolo criado por Guimarães et al. (2006) vem sendo utilizado nas atividades de EA em outros projetos, como o "Manuelzão", cujo principal objetivo é a revitalização da bacia do Rio das Velhas, vinculado à Universidade Federal de Minas Gerais (UFMG) e em projetos educacionais da empresa de turismo pedagógico Estação Terra que presta assessoria em EA para escolas do ensino infantil, fundamental e médio na região metropolitana de Belo Horizonte.

Contudo, o PAR utilizado no estudo de Guimarães et al. (2006) foi adequado para ser aplicado em condições bem específicas da bacia hidrográfica da Pampulha, não podendo, dessa forma, ser utilizado em projetos de EA em outras regiões no Brasil. No Estado de Goiás, cujo bioma predominante é o Cerrado, nenhum trabalho semelhante foi desenvolvido. Assim, o presente estudo teve como objetivo adequar um PAR para uso por crianças matriculadas no ensino fundamental. Acredita-se que o PAR adequado possa ser útil na promoção da observação, sensibilização e apropriação de conceitos referentes ao funcionamento, por parte dos discentes, e na preservação dos recursos fluviais, contribuindo significativamente com o desenvolvimento da EA no nível básico da educação.

\section{MATERIAL E MÉTODOS}

\section{1. Área de estudo}

O presente estudo foi desenvolvido na cidade de Ipameri-GO cujo município está localizado entre os rios Corumbá e São Marcos, tendo como coordenadas geográficas $17^{\circ} 43^{\prime} 20^{\prime \prime}$ de latitude Sul e 48 $09^{\prime} 44^{\prime \prime}$ de longitude Oeste. Além do distrito sede, constituído hoje por 18 bairros e 17 vilas, o município conta também com mais dois distritos, Cavalheiro e Domiciano Ribeiro, e 5 povoados na zona rural: Tomazinópolis, Vila Pacheco, Vendinha, São Sebastião da União e Lago Azul (Ipameri, 2010). Demograficamente, Ipameri possui, 
GUIMARÃES, A.; RODRIGUES, A. S. L.; MALAFAIA, G. Adequação de um protocolo de avaliação rápida de rios para ser usado por estudantes do ensino fundamental. Ambi-Agua, Taubaté, v. 7, n. 3, p. 241-260, 2012. (http://dx.doi.org/10.4136/ambi-agua.996)

segundo dados do último censo realizado pelo Instituto Brasileiro de Geografia e Estatística (IBGE), aproximadamente 24.800 habitantes (IBGE, 2010).

O município está localizado sobre uma formação rochosa antiga e apresenta $45 \%$ de seu território com topografia plana, $40 \%$ ondulada e os $15 \%$ restantes montanhosa. A altitude média na quase totalidade do território municipal está na faixa de $800 \mathrm{~m}$. As principais elevações existentes são a Serra Patrona, a Serra da Arnica, a Serra da Mangaba, o Morro de São Domingos, o Morro do Brito e o Contraforte Central (Ipameri, 2010).

O clima de Ipameri pode ser considerado tipicamente tropical-úmido, com temperatura média de $25^{\circ} \mathrm{C}$. A precipitação pluviométrica anual é de $1750 \mathrm{~mm}$, com ocorrência de $80 \%$ das chuvas nos meses de dezembro, janeiro e março, e o restante se distribuindo principalmente nos meses de outubro, novembro e fevereiro (Ipameri, 2010).

\subsection{Seleção dos pontos, aplicação dos protocolos referências e adequação do novo protocolo}

Foram selecionados como referências que norteariam a adequação do PAR no presente estudo, os protocolos elaborados por Barbour et al. (1999) e Rodrigues e Castro (2008b) (versões aplicáveis a cursos d'água de baixo curso) ${ }^{1}$. Inicialmente, tais protocolos foram aplicados em 27 trechos de rios da cidade de Ipameri, GO por três avaliadores previamente treinados (Tabela 1). Os critérios de seleção destes pontos foram relacionados à distribuição espacial homogênea na rede hidrográfica da cidade e a facilidade de acesso aos mesmos.

Tabela 1. Pontos e coordenadas geográficas dos trechos de rios visitados na cidade de Ipameri, GO.

\begin{tabular}{|c|c|c|c|}
\hline Identificação & Coordenadas & Identificação & Coordenadas \\
\hline 1 & $48^{\circ} 10^{\prime} 19^{\prime \prime}$ O $17^{\circ} 42^{\prime} 19^{\prime \prime} \mathrm{S}$ & 15 & $48^{\circ} 09^{\prime} 43^{\prime \prime}$ O 17'43'03', S \\
\hline 2 & $48^{\circ} 10^{\prime} 18^{\prime \prime} \mathrm{O} 17^{\circ} 42^{\prime} 20^{\prime \prime} \mathrm{S}$ & 16 & $48^{\circ} 09^{\prime} 53^{\prime \prime} \mathrm{O} 17^{\circ} 43^{\prime} 05^{\prime \prime} \mathrm{S}$ \\
\hline 3 & $48^{\circ} 10^{\prime} 05^{\prime \prime} \mathrm{O} 17^{\circ} 42^{\prime} 58^{\prime \prime} \mathrm{S}$ & 17 & $48^{\circ} 09^{\prime} 53^{\prime \prime} \mathrm{O} 17^{\circ} 43^{\prime} 05^{\prime}, \mathrm{S}$ \\
\hline 4 & $48^{\circ} 09^{\prime} 05^{\prime \prime} \mathrm{O} 17^{\circ} 42^{\prime} 23^{\prime \prime} \mathrm{S}$ & 18 & $48^{\circ} 10^{\prime} 011^{\prime}$ O 17 $43^{\circ} 05^{\prime}, \mathrm{S}$ \\
\hline 5 & $48^{\circ} 09^{\prime} 05^{\prime \prime} \mathrm{O} 17^{\circ} 42^{\prime} 25^{\prime}, \mathrm{S}$ & 19 & $48^{\circ} 10^{\prime} 02^{\prime \prime} \mathrm{O} 17^{\circ} 43^{\prime} 05^{\prime \prime} \mathrm{S}$ \\
\hline 6 & $48^{\circ} 09^{\prime} 06^{\prime \prime} \mathrm{O} 17^{\circ} 42^{\prime} 40^{\prime \prime} \mathrm{S}$ & 20 & $48^{\circ} 09^{\prime} 55^{\prime \prime}$ O 17\%43'14', S \\
\hline 7 & 4809'09', O 17'42'40', S & 21 & $48^{\circ} 09^{\prime} 55^{\prime \prime} \mathrm{O} 17^{\circ} 43^{\prime} 15^{\prime}, \mathrm{S}$ \\
\hline 8 & $48^{\circ} 09^{\prime} 12^{\prime \prime} \mathrm{O} 17^{\circ} 42^{\prime} 42^{\prime \prime} \mathrm{S}$ & 22 & $48^{\circ} 09^{\prime} 57^{\prime \prime} \mathrm{O} 17^{\circ} 43^{\prime} 22^{\prime \prime} \mathrm{S}$ \\
\hline 9 & 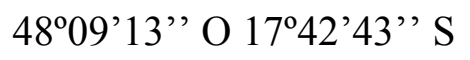 & 23 & $48^{\circ} 09^{\prime} 57^{\prime \prime} \mathrm{O} 17^{\circ} 43^{\prime} 23^{\prime \prime} \mathrm{S}$ \\
\hline 10 & $48^{\circ} 09^{\prime} 27^{\prime \prime} \mathrm{O} 17^{\circ} 42^{\prime} 57^{\prime \prime} \mathrm{S}$ & 24 & $48^{\circ} 10^{\prime} 01^{\prime \prime} \mathrm{O} 17^{\circ} 43^{\prime} 33^{\prime \prime} \mathrm{S}$ \\
\hline 11 & $48^{\circ} 09^{\prime} 28^{\prime \prime} \mathrm{O} 17^{\circ} 42^{\prime} 57^{\prime \prime} \mathrm{S}$ & 25 & $48^{\circ} 10^{\prime} 011^{\prime \prime O ~} 17^{\circ} 43^{\prime} 33^{\prime \prime} \mathrm{S}$ \\
\hline 12 & $48^{\circ} 09^{\prime} 40^{\prime \prime} \mathrm{O} 17^{\circ} 43^{\prime} 01^{\prime}, \mathrm{S}$ & 26 & $48^{\circ} 10^{\prime} 05^{\prime \prime} \mathrm{O} 17^{\circ} 43^{\prime} 47^{\prime \prime} \mathrm{S}$ \\
\hline 13 & $48^{\circ} 09^{\prime} 41^{\prime \prime} \mathrm{O} 17^{\circ} 43^{\prime} 01^{\prime}, \mathrm{S}$ & 27 & $48^{\circ} 10^{\prime} 05^{\prime \prime}$ O $17^{\circ} 43^{\prime} 48^{\prime \prime} \mathrm{S}$ \\
\hline 14 & $48^{\circ} 09^{\prime} 43^{\prime \prime} \mathrm{O} 17^{\circ} 43^{\prime} 03^{\prime \prime} \mathrm{S}$ & & \\
\hline
\end{tabular}

\footnotetext{
${ }^{1}$ O PAR de Barbour et al. (1999) é qualificado por uma compilação de vários métodos de avaliação rápida de rios existentes utilizados em várias regiões temperadas dos Estados Unidos por agências ambientais estaduais deste país. Já o PAR de Rodrigues e Castro (2008b) refere-se à proposição de um PAR desenvolvido para a avaliação de cursos d'água inseridos em campos rupestres (Cerrado) do Estado de Minas Gerais. A escolha desses dois trabalhos se deu em função de características específicas de cada um. Enquanto o primeiro trata-se do PAR que pioneiramente foi introduzido no Brasil e em outros países como proposta de avaliação integrada e complementar da qualidade dos recursos fluviais, o segundo trata-se de um protocolo que foi adaptado para uso em uma variação do bioma Cerrado, fato este que o aproxima das características fitofisionômicas de Ipameri, GO (área de estudo). O protocolo proposto por Callisto et al. (2002), muito utilizado por diversos estudos que dispuseram avaliar as condições ambientais de cursos d'água no Brasil, não foi utilizado no presente trabalho como referência uma vez que ele foi adaptado para o contexto da Mata Atlântica (Serrada Bocaina), bioma diferente do que predomina em Ipameri, GO.
} 
Em seguida, partiu-se para a adequação do novo protocolo. Tal adequação foi realizada levando-se em consideração a definição de quais parâmetros presentes nos protocolos referências seriam mantidos ou excluídos e quais poderiam ser incluídos; a definição das notas possíveis de serem atribuídas aos trechos; a categorização do gradiente de estresse ambiental condizente com as notas e essas com as possíveis condições ambientais dos trechos ("ruim", "boa" ou "ótima"); a adequação da linguagem da descrição dos parâmetros abordados no PAR, compatível ao nível de escolaridade do ensino fundamental; a elaboração de figuras que poderiam auxiliar o avaliador no momento da aplicação do PAR e, por fim, a consolidação do protocolo adequado, por meio de uma oficina de monitoramento ambiental.

\subsection{Oficina de monitoramento ambiental e consolidação do novo protocolo}

Uma oficina de monitoramento ambiental foi oferecida a 95 alunos do ensino fundamental $\left(6^{\circ}, 7^{\circ}, 8^{\circ}\right.$ e $9^{\circ}$ anos), em duas instituições de ensino de Ipameri, GO (Colégio Estadual Professor Eduardo Mancini e Escola Municipal Godofredo Perfeito). A oficina, além de oferecer aos participantes a oportunidade de ampliar seus conhecimentos específicos sobre monitoramento ambiental e funcionamento dos sistemas fluviais, também serviu para avaliar a aplicabilidade do PAR adequado, de modo a identificar possíveis falhas, adequá-las e, por fim, consolidar o protocolo desenvolvido. Tal oficina foi realizada em duas etapas.

Na primeira, adotou-se uma abordagem teórica tendo sido apresentado aos estudantes os objetivos e justificativas do presente trabalho, a relevância do monitoramento dos rios, definições de indicadores ambientais, índices de integridade ambiental, o histórico dos protocolos, bem como suas vantagens e características, além dos parâmetros a serem analisados em campo na etapa prática da oficina. $\mathrm{O}$ material de apoio didático da oficina contou com um roteiro, em forma de apostila que continha informações sobre o uso dos protocolos, instruções sobre a aplicação do PAR adequado e um guia visual composto por fotografias e exemplos de diferentes situações ambientais. Para facilitar a utilização do protocolo pelos voluntários, para cada parâmetro considerado no protocolo adequado, havia uma breve descrição do mesmo.

$\mathrm{Na}$ segunda etapa, os estudantes que participaram do treinamento teórico foram a campo aplicar - em um mesmo trecho (ponto 7 - coordenadas 48 $09^{\prime} 09^{\prime \prime} \mathrm{O} 17^{\circ} 42^{\prime} 40^{\prime}$ ' S) - o protocolo adequado. Ressalta-se que o intuito dessa etapa não foi realizar um diagnóstico das condições ambientais dos cursos d'água da cidade de Ipameri, GO a partir da avaliação dos discentes participantes da oficina de monitoramento ambiental. Neste caso, objetivou especificamente avaliar a consistência do PAR desenvolvido, o entendimento dos parâmetros e da descrição de cada um deles pelos discentes, bem como a opinião geral dos discentes quanto ao instrumento adequado.

Cada discente realizou a aplicação do protocolo individualmente. Para a consolidação do protocolo desenvolvido foi realizada uma análise e interpretação do padrão de respostas obtidas nesta etapa prática, partindo-se do pressuposto de que variações significativas entre as respostas dos estudantes poderiam indicar falhas no protocolo. Para a verificação da convergência das respostas entre os avaliadores, considerou-se a observação de um padrão de respostas similares. Para isso, os dados da aplicação do PAR pelos discentes foram submetidos à análise de igualdade de variâncias, utilizando-se os testes de Bartlett's (Snedecor e Cochran, 1989) e Levene (Brown e Forsythe, 1974), de forma semelhante à metodologia adotada por Rodrigues e Castro (2008b). Foram consideradas variações estatisticamente significativas entre as médias das respostas dos avaliadores, valores de $p$ menores que 0,05 .

Além disso, comparou-se o resultado da avaliação do trecho de rio realizada pelos discentes com os resultados obtidos do diagnóstico ambiental desse mesmo trecho realizado por Firmino et al. (2011). Partiu-se da ideia de que a consolidação do PAR necessitava se dar 
por meio de evidências que não apenas mostrassem a não variação do padrão de respostas da avaliação realizada pelos discentes, mas também que mostrassem a coerência da avaliação dos alunos do ponto de vista técnico.

Ao final desta atividade os voluntários responderam um questionário (Quadro 1) que forneceu informações que serviram para consolidação do instrumento adequado, além de permitir a identificação de opiniões dos participantes sobre a oficina de monitoramento ambiental oferecida.

Quadro 1. Questionário aplicado junto aos alunos participantes da oficina de monitoramento ambiental.

\begin{tabular}{|c|c|}
\hline 1) Nome da Escola: & 2) Série: \\
\hline 3) Sexo: ( ) masculino ( ) feminino & 4) Idade: \\
\hline $\begin{array}{l}\text { 5) Quanto tempo você gastou para aplicar } \\
\text { o protocolo? } \\
\text { ( ) Menos de } 20 \text { minutos } \\
\text { ( ) Entre } 20 \text { e } 40 \text { minutos } \\
\text { ( ) Entre } 40 \text { minutos e } 1 \text { hora } \\
\text { ( ) Mais de } 1 \text { hora }\end{array}$ & $\begin{array}{l}\text { 6) Você acredita que a utilização do protocolo é um meio } \\
\text { que o aproxima das questões ambientais? } \\
\text { ( ) Sim ( ) Não } \\
\text { Comentário: }\end{array}$ \\
\hline $\begin{array}{l}\text { 7) As instruções da oficina de } \\
\text { monitoramento ambiental ajudaram na } \\
\text { melhor compreensão do instrumento? } \\
\text { ( ) Sim ( ) Não } \\
\text { Comentário: }\end{array}$ & $\begin{array}{l}\text { 8) As ilustrações disponíveis em cada parâmetro o } \\
\text { ajudaram durante a avaliação em campo e durante a } \\
\text { atribuição de notas aos parâmetros? } \\
\text { ( ) Sim ( ) Não } \\
\text { Comentário: }\end{array}$ \\
\hline $\begin{array}{l}\text { 9) Durante a avaliação do rio com o } \\
\text { protocolo, você se sentiu um agente } \\
\text { colaborador na defesa de um rio? } \\
\text { ( ) Sim ( ) Não } \\
\text { Comentário: }\end{array}$ & $\begin{array}{l}\text { 10) A participação na oficina de monitoramento } \\
\text { ambiental permitiu a apropriação de conhecimentos } \\
\text { sobre o funcionamento dos sistemas fluviais? } \\
\text { ( ) Sim ( ) Não } \\
\text { Comentário: }\end{array}$ \\
\hline $\begin{array}{l}\text { 11) Você apresentou alguma dificuldade } \\
\text { de entendimento dos parâmetros } \\
\text { propostos no PAR? } \\
\text { ( ) Sim ( ) Não } \\
\text { Se sim, qual(is) foi(ram) esse(s) } \\
\text { parâmetro(s)? }\end{array}$ & $\begin{array}{l}\text { 12) Você acredita que qualquer pessoa previamente } \\
\text { treinada pode realizar a avaliação de um rio utilizando-se } \\
\text { este PAR? } \\
\text { ( ) Sim ( ) Não } \\
\text { Comentário: }\end{array}$ \\
\hline
\end{tabular}

\subsection{Questões éticas}

Considerando que parte desse trabalho envolveu a participação de seres humanos, o projeto que deu origem a esse estudo foi submetido para análise e parecer do Comitê de Ética em Pesquisa (CEP) do IF Goiano, sob o protocolo $n^{\circ}$ 001, tendo sido aprovado em 27 de dezembro de 2010.

\section{RESULTADOS E DISCUSSÃO}

A partir das visitas a campo e da aplicação dos PARs referências em trechos de rios da cidade de Ipameri, GO, evidenciou-se, de um modo geral, uma grande variação das pontuações atribuídas a cada parâmetro pelos três avaliadores (Figura 1). A título de demonstração dos resultados referentes a essas aplicações, foram escolhidos, aleatoriamente, os dados obtidos na avaliação de dois trechos de rios, considerando a existência de uma similaridade entre os resultados obtidos para todos os trechos visitados e a impossibilidade da utilização desses dados como condizentes com as condições ambientais locais, já que os 
protocolos aplicados foram criados para uso em um contexto fitofisionômico diferente do que se observa em Ipameri, GO.

A variação observada pode ser explicada, neste caso, pela incoerência entre a descrição das categorias estabelecidas nos PARs aplicados e as características verificadas nos trechos, o que dificultou a associação da situação real verificada a uma categoria de avaliação específica ("ótima", "sub-ótima", "razoável” e "pobre"), além do fato de que os PARs aplicados foram propostos para avaliação de rios inseridos em fitofisionomias de biomas diferentes do considerado no presente estudo (Cerrado do Sudeste goiano). O intuito dessa etapa foi verificar se os protocolos referências poderiam ter diretamente suas linguagens adequadas ao nível do ensino fundamental, ou se antes, deveriam ocorrer também adequações técnicas, no que tange aos parâmetros propostos, suas descrições, o gradiente de estresse ambiental proposto em cada documento e as categorias de condições ambientais nas quais os trechos são enquadrados.

Os Quadros 2 e 3 sumarizam os principais resultados qualitativos obtidos a partir das visitas a campo, referentes à aplicação dos PARs.
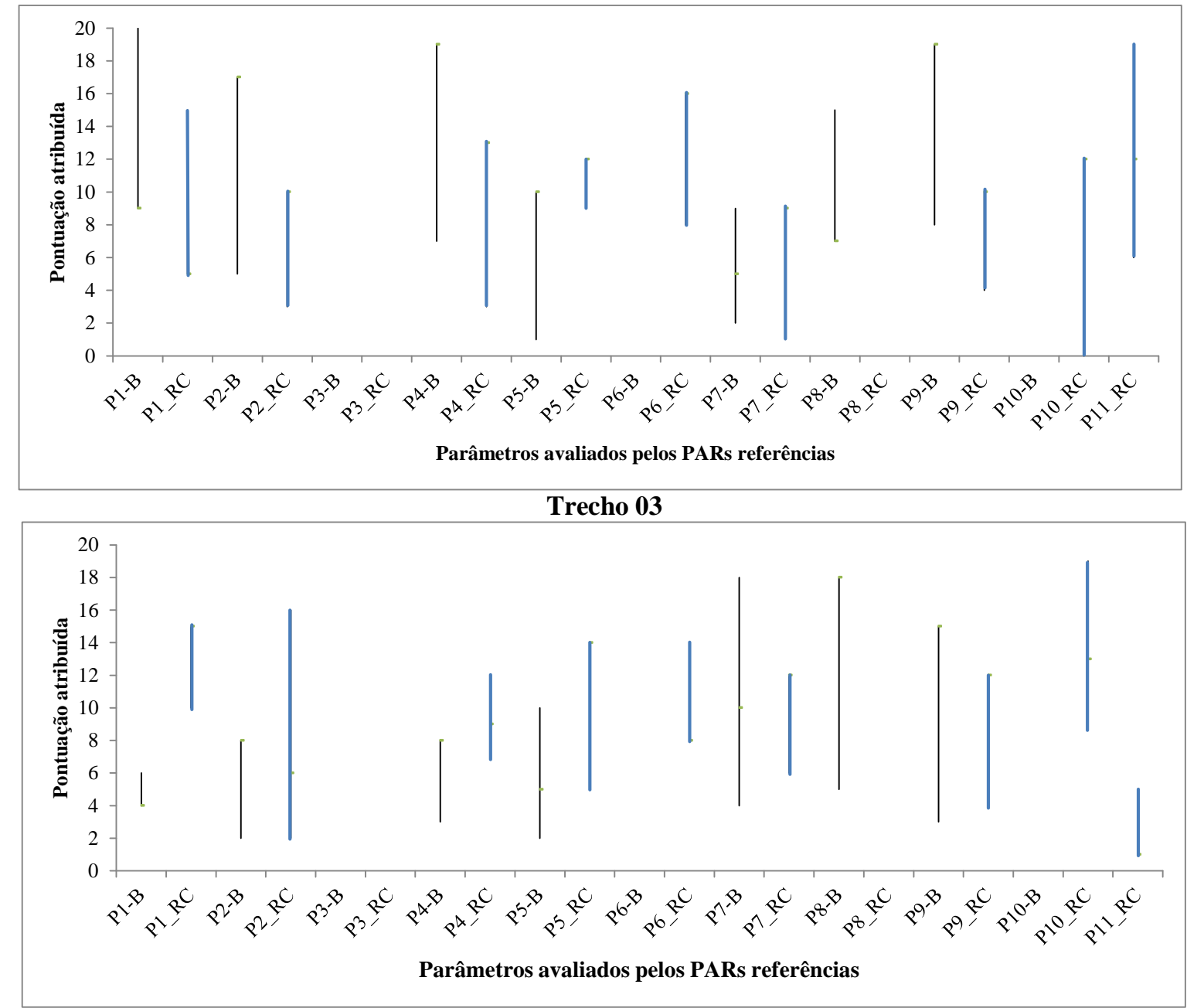

\section{Trecho 09}

Figura 1. Variação das pontuações atribuídas pelos três avaliadores aos parâmetros analisados pelos protocolos referência em dois trechos de rios localizados na cidade de Ipameri, GO. ${ }^{1,2,3,4}$

Nota: ${ }^{1}$ As barras verticais indicam a variação (máximo e mínimo) das pontuações atribuídas pelos três avaliadores. Optou-se por não apresentar a média +/- desvio padrão devido ao número pequeno de avaliações $(\mathrm{n}=3)$ realizadas no mesmo trecho de rio.

${ }^{2}$ As barras verticais pretas indicam os resultados obtidos por meio do PAR de Barbour et al. (1999) e as barras azuis os obtidos por meio do PAR de Rodrigues e Castro (2008b).

${ }^{3}$ Os parâmetros (P1, P2 (...) P11) discriminados na abscissa não são coincidentes nos PARs aplicados nos trechos de rios sob avaliação.

${ }^{4}$ A inicial "B" refere-se aos parâmetros propostos no PAR de Barbour et al. (1999) e as iniciais "RC" referem-se aos parâmetros propostos no PAR de Rodrigues e Castro (2008b). 
GUIMARÃES, A.; RODRIGUES, A. S. L.; MALAFAIA, G. Adequação de um protocolo de avaliação rápida de rios para ser usado por estudantes do ensino fundamental. Ambi-Agua, Taubaté, v. 7, n. 3, p. 241-260, 2012. (http://dx.doi.org/10.4136/ambi-agua.996)

Quadro 2 - Resultados referentes à aplicação do PAR de Barbour et al. (1999) em trechos de rios localizados na cidade de Ipameri, GO.

\begin{tabular}{|c|c|}
\hline $\begin{array}{l}\text { Parâmetros e/ou } \\
\text { características do } \\
\text { instrumento }\end{array}$ & Principais resultados/observações ${ }^{*}$ \\
\hline $\begin{array}{l}\text { O referido protocolo } \\
\text { apresenta duas versões } \\
\text { para avaliação: uma deve } \\
\text { ser aplicada em rios de } \\
\text { baixo curso e a outra em } \\
\text { rios de alto curso }\end{array}$ & $\begin{array}{l}\text { Para a área de estudo optou-se por adequar um protocolo a ser aplicado apenas } \\
\text { em rios com características de baixo curso. Os cursos d'água observados na } \\
\text { região de Ipameri, GO fazem parte de uma paisagem de baixa declividade. Via } \\
\text { de regra, possuem um perfil longitudinal de baixo gradiente, isto é, com pequeno } \\
\text { desnível entre as nascentes e a barragem. Possuem poucas corredeiras e } \\
\text { cachoeiras de modo que a velocidade do escoamento é basicamente em função de } \\
\text { seu volume, e, portanto, da dimensão da bacia de captação e do regime } \\
\text { pluviométrico regional. }\end{array}$ \\
\hline $\begin{array}{l}\text { Parâmetro 1: "Epifaunal } \\
\text { substratel Available } \\
\text { Cover" }\end{array}$ & $\begin{array}{l}\text { Apresenta descrição técnica que se baseia na distinção de percentuais subjetivos } \\
\text { que deveriam ser condizentes com a avaliação ambiental verificada in situ. Além } \\
\text { disso, conceitos como, por exemplo, os de "habitats estáveis", considerados } \\
\text { complexos ao nível de escolaridade do nível fundamental, foram evidenciados na } \\
\text { descrição das categorias de condição ambiental para esse parâmetro. }\end{array}$ \\
\hline $\begin{array}{l}\text { Parâmetro 2: "Pool } \\
\text { substrate } \\
\text { Characterization" }\end{array}$ & $\begin{array}{l}\text { O referido parâmetro apresenta conteúdo técnico considerado complexo ao nível } \\
\text { de escolaridade do nível fundamental. Além disso, a avaliação deste parâmetro } \\
\text { em determinadas épocas do ano (em virtude da cheia dos rios e do aumento da } \\
\text { turbidez das águas, por exemplo) pode ser comprometida. }\end{array}$ \\
\hline $\begin{array}{l}\text { Parâmetro 3: "Pool } \\
\text { Variability" }\end{array}$ & $\begin{array}{l}\text { Este parâmetro apresenta descrição subjetiva. A definição, por exemplo, do que } \\
\text { seriam poços largos e/ou grandes, pequenos e/ou rasos, não é muito clara, o que } \\
\text { dificulta a avaliação do trecho considerando esse parâmetro. Esse parâmetro não } \\
\text { foi aplicável utilizando-se o PAR de Barbour et al. (1999). }\end{array}$ \\
\hline $\begin{array}{l}\text { Parâmetro 4: "Sediment } \\
\text { Deposition" }\end{array}$ & $\begin{array}{l}\text { Refere-se a um parâmetro que foi incorporado ao PAR proposto no presente } \\
\text { estudo, de modo em que foi diminuída a subjetividade da descrição das } \\
\text { categorias relativas a este parâmetro e o número de categorias de condições } \\
\text { ambientais que podem ser atribuídas ao trecho referente especificamente a este } \\
\text { parâmetro. }\end{array}$ \\
\hline $\begin{array}{l}\text { Parâmetro 5: "Channel } \\
\text { Alteration" }\end{array}$ & Idem aos resultados/comentários referentes ao Parâmetro "Sediment Deposition" \\
\hline $\begin{array}{l}\text { Parâmetro 6: "Channel } \\
\text { Flow Status" }\end{array}$ & $\begin{array}{l}\text { O referido parâmetro apresenta descrição subjetiva, cuja medição pode ser } \\
\text { dificultada ou sujeita a erros utilizando-se apenas a visibilidade do avaliador. } \\
\text { Esse parâmetro não foi aplicável à área de estudo utilizando-se o PAR de } \\
\text { Barbour et al. (1999). }\end{array}$ \\
\hline $\begin{array}{l}\text { Parâmetro 7: "Channel } \\
\text { Sinuosity" }\end{array}$ & $\begin{array}{l}\text { Este parâmetro não foi considerado no PAR proposto no presente estudo em } \\
\text { função da dificuldade de avaliar o grau de sinuosidade dos rios a partir de uma } \\
\text { avaliação realizada nas margens do curso d'água (como é o caso da aplicação dos } \\
\text { PARs). Entende-se que uma avaliação mais condizente deva ser feito a partir de } \\
\text { imagens de satélite onde uma visão mais ampla é possibilitada. }\end{array}$ \\
\hline $\begin{array}{l}\text { Parâmetro 8: "Bank } \\
\text { Stability (score each } \\
\text { bank)" }\end{array}$ & Idem aos resultados/comentários referentes ao Parâmetro "Sediment Deposition" \\
\hline $\begin{array}{l}\text { Parâmetro 9: "Vegetative } \\
\text { Protection (score each } \\
\text { bank)" }\end{array}$ & Idem aos resultados/comentários referentes ao Parâmetro "Sediment Deposition" \\
\hline $\begin{array}{l}\text { Parâmetro 10: "Riparian } \\
\text { Vegetative Zone Width } \\
\text { (score each bank } \\
\text { riparian zone)" }\end{array}$ & Idem aos resultados/comentários referentes ao Parâmetro "Sediment Deposition" \\
\hline
\end{tabular}

Nota: * Os resultados/comentários apresentados neste quadro foram elaborados a partir de anotações diversas realizadas pela equipe executora do estudo durante a visitação dos 27 trechos de rios localizados na cidade de Ipameri, GO. 
GUIMARÃES, A.; RODRIGUES, A. S. L.; MALAFAIA, G. Adequação de um protocolo de avaliação rápida de rios para ser usado por estudantes do ensino fundamental. Ambi-Agua, Taubaté, v. 7, n. 3, p. 241-260, 2012. (http://dx.doi.org/10.4136/ambi-agua.996)

Quadro 3 - Resultados referentes à aplicação do PAR de Rodrigues e Castro (2008a) em trechos de rios localizados na cidade de Ipameri, GO

\begin{tabular}{|c|c|}
\hline $\begin{array}{l}\text { Parâmetros e/ou características } \\
\text { do instrumento }\end{array}$ & Principais resultados/observações* \\
\hline $\begin{array}{l}\text { O referido protocolo, assim como o } \\
\text { PAR de Barbour et al. (1999), } \\
\text { apresenta duas versões: uma deve ser } \\
\text { aplicada em rios de baixo curso e outra } \\
\text { em rios de alto curso }\end{array}$ & $\begin{array}{l}\text { Idem aos resultados/comentários apresentados, no Quadro 1, para } \\
\text { essa característica. }\end{array}$ \\
\hline $\begin{array}{l}\text { Parâmetro 1: "Substratos e/ou habitats } \\
\text { disponíveis" }\end{array}$ & $\begin{array}{l}\text { Refere-se a um parâmetro que foi incorporado ao PAR proposto no } \\
\text { presente estudo, de modo em que foi diminuída a subjetividade da } \\
\text { descrição das categorias relativas a este parâmetro (baseada na } \\
\text { distinção de percentuais referentes à quantidade de substratos e/ou } \\
\text { habitats disponíveis no trecho sob avaliação) e o número de } \\
\text { categorias de condições ambientais que podem ser atribuídas ao } \\
\text { trecho referente especificamente a este parâmetro. }\end{array}$ \\
\hline Parâmetro 2: "Substratos em poços" & $\begin{array}{l}\text { Esse parâmetro não foi considerado no PAR adequado no presente } \\
\text { estudo, pois envolve conceitos subjetivos como aqueles relativos ao } \\
\text { que seriam, para a área de estudo, "poços de vários tipos e tamanhos } \\
\text { de substratos". }\end{array}$ \\
\hline $\begin{array}{l}\text { Parâmetro 3: "Regimes de } \\
\text { velocidade/profundidade" }\end{array}$ & $\begin{array}{l}\text { O referido parâmetro apresenta descrição subjetiva, cuja medição } \\
\text { pode ser dificultada ou sujeita a erros utilizando-se apenas a } \\
\text { visibilidade do avaliador. Esse parâmetro não foi aplicável à área de } \\
\text { estudo utilizando-se o PAR de Rodrigues e Castro (2008b). }\end{array}$ \\
\hline Parâmetro 4: "Diversidade de poços" & $\begin{array}{l}\text { Esse parâmetro não foi considerado no PAR adequado no presente } \\
\text { estudo, pois apresenta conceitos subjetivos como aqueles relativos ao } \\
\text { que seriam, para a área de estudo, "diferentes tipos e tamanho de } \\
\text { poços". }\end{array}$ \\
\hline $\begin{array}{l}\text { Parâmetro 5: "Deposição de } \\
\text { sedimentos" }\end{array}$ & $\begin{array}{l}\text { Idem aos resultados/comentários referentes ao Parâmetro "Substratos } \\
\text { e/ou habitat disponíveis" }\end{array}$ \\
\hline $\begin{array}{l}\text { Parâmetro 6: "Condições de } \\
\text { escoamento do canal" }\end{array}$ & $\begin{array}{l}\text { O referido parâmetro apresenta conteúdo técnico considerado } \\
\text { complexo ao nível de escolaridade do nível fundamental e descrição } \\
\text { subjetiva, o que dificulta a sua mensuração. }\end{array}$ \\
\hline Parâmetro 7: "Alterações no canal” & $\begin{array}{l}\text { Idem aos resultados/comentários referentes ao Parâmetro "Substratos } \\
\text { e/ou habitat disponíveis" }\end{array}$ \\
\hline Parâmetro 8: "Sinuosidade do canal" & $\begin{array}{l}\text { Este parâmetro não foi considerado no PAR proposto no presente } \\
\text { estudo em função da dificuldade de avaliar o grau de sinuosidade dos } \\
\text { rios a partir de uma avaliação realizada nas margens do curso d'água } \\
\text { (como é o caso da aplicação dos PARs). Entende-se que uma } \\
\text { avaliação mais condizente deva ser feito a partir de imagens de } \\
\text { satélite onde uma visão mais ampla é possibilitada. }\end{array}$ \\
\hline $\begin{array}{l}\text { Parâmetro 9: "Estabilidade das } \\
\text { margens" }\end{array}$ & $\begin{array}{l}\text { Idem aos resultados/comentários referentes ao Parâmetro "Substratos } \\
\text { e/ou habitat disponíveis" }\end{array}$ \\
\hline $\begin{array}{l}\text { Parâmetro 10: "Proteção das margens } \\
\text { pela vegetação" }\end{array}$ & $\begin{array}{l}\text { Idem aos resultados/comentários referentes ao Parâmetro "Substratos } \\
\text { e/ou habitat disponíveis" }\end{array}$ \\
\hline $\begin{array}{l}\text { Parâmetro 11: "Estado de conservação } \\
\text { da vegetação do entorno" }\end{array}$ & $\begin{array}{l}\text { Idem aos resultados/comentários referentes ao Parâmetro "Substratos } \\
\text { e/ou habitat disponíveis" }\end{array}$ \\
\hline
\end{tabular}

Nota: * Os resultados/comentários apresentados neste quadro foram elaborados a partir de anotações diversas realizadas pela equipe executora do estudo durante a visitação dos 27 trechos de rios localizados na cidade de Ipameri, GO. 
GUIMARÃES, A.; RODRIGUES, A. S. L.; MALAFAIA, G. Adequação de um protocolo de avaliação rápida de rios para ser usado por estudantes do ensino fundamental. Ambi-Agua, Taubaté, v. 7, n. 3, p. 241-260, 2012. (http://dx.doi.org/10.4136/ambi-agua.996)

Após a constatação da necessidade de alterações nos PARs referências, além das adequações relativas à linguagem técnica, um novo PAR foi adequado. Este PAR abrange a avaliação de onze parâmetros, cujas avaliações podem refletir condições consideradas "ótimas", "boas" ou "ruins". São eles: "Características do fundo do rio", "Sedimentos no fundo do rio", "Ocupação das margens do rio", "Erosão", "Lixo", "Alterações no canal do riacho", "Esgoto doméstico ou industrial", "Oleosidade da água", "Plantas aquáticas", "Animais" e "Odor da água". O PAR adequado pode ser observado na íntegra no Quadro 4. Ressalta-se que a partir da descrição de cada parâmetro proposto é possível atribuir notas condizentes com as condições observadas no trecho de rio em avaliação.

Destaca-se que a pontuação aumenta na mesma proporção da qualidade do habitat, e pode variar de acordo com o local das observações. Para os parâmetros cuja avaliação envolve as margens do canal (esquerda e direita) a pontuação deve ser atribuída a cada margem separadamente. Neste caso, as margens poderão apresentar diferentes condições ambientais e a avaliação do trecho é obtida por meio da média aritmética das pontuações.

O resultado final do protocolo proposto é obtido a partir do somatório dos valores atribuídos a cada parâmetro avaliado. A pontuação final reflete a condição ambiental encontrada nos trechos de rios avaliados. Trechos cujas pontuações, quando somadas encontram-se no intervalo entre 71 e 110 deverão ser considerados "ótimos" (ou seja, refletem uma condição natural ou com pouca alteração antrópica), quando no intervalo entre 31 e 70 , "bons" e quando no intervalo entre 0 e 30 , "ruins".

Com o intuito de facilitar a compreensão dos aspectos que devem ser avaliados em cada parâmetro, optou-se por apresentar, junto de cada um, desenhos esquemáticos como exemplos de condições ambientais possíveis de serem identificadas em campo (Quadro 4).

Quadro 4 - Protocolo de avaliação rápida adequado.

\begin{tabular}{|c|c|c|}
\hline \multirow{2}{*}{\multicolumn{3}{|c|}{$\begin{array}{l}\text { Nome do avaliador: } \\
\text { Nome da escola: }\end{array}$}} \\
\hline & & \\
\hline \multicolumn{3}{|l|}{$\begin{array}{l}\text { Nome da escola: } \\
\text { Data da avaliaçã }\end{array}$} \\
\hline \multicolumn{3}{|c|}{$\begin{array}{l}\text { Instruções: Você agora é um pesquisador e deve avaliar a saúde de rios e riachos. Por onde começar? Este } \\
\text { protocolo é utilizado por pesquisadores em todo o mundo, e agora será utilizado por você. Leia atentamente } \\
\text { os parâmetros e depois de observado o rio ao redor, marque uma nota ( } 10,5 \text { ou } 0) \text {, de acordo com a situação } \\
\text { verificada. }\end{array}$} \\
\hline \multicolumn{3}{|c|}{ Parâmetro 1: Características do fundo do rio } \\
\hline Ótima & Boa & Ruim \\
\hline $\begin{array}{l}\text { Existem galhos ou troncos, } \\
\text { cascalhos (pedras), folhas e } \\
\text { plantas aquáticas no fundo do rio. }\end{array}$ & $\begin{array}{l}\text { Há poucos galhos ou troncos, } \\
\text { cascalhos (pedras) no fundo do rio. }\end{array}$ & $\begin{array}{l}\text { Não existem galhos ou troncos, } \\
\text { cascalhos (pedras), folhas e } \\
\text { plantas aquáticas no fundo do } \\
\text { rio. }\end{array}$ \\
\hline 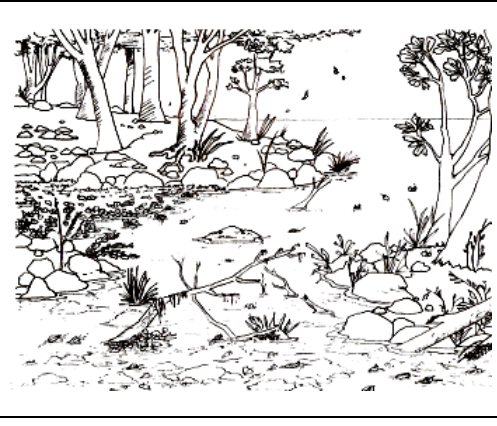 & 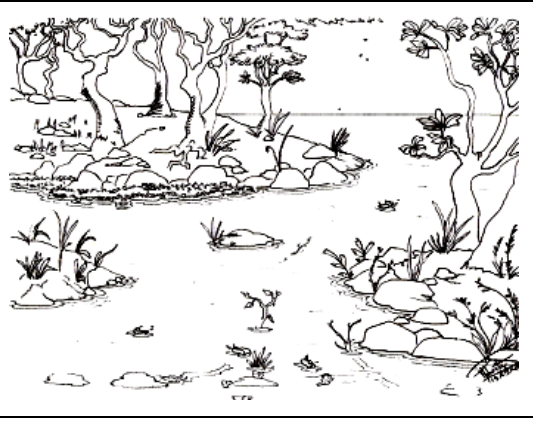 & (1) \\
\hline 10 & 5 & 0 \\
\hline
\end{tabular}


GUIMARÃES, A.; RODRIGUES, A. S. L.; MALAFAIA, G. Adequação de um protocolo de avaliação rápida de rios para ser usado por estudantes do ensino fundamental. Ambi-Agua, Taubaté, v. 7, n. 3, p. 241-260, 2012. (http://dx.doi.org/10.4136/ambi-agua.996)

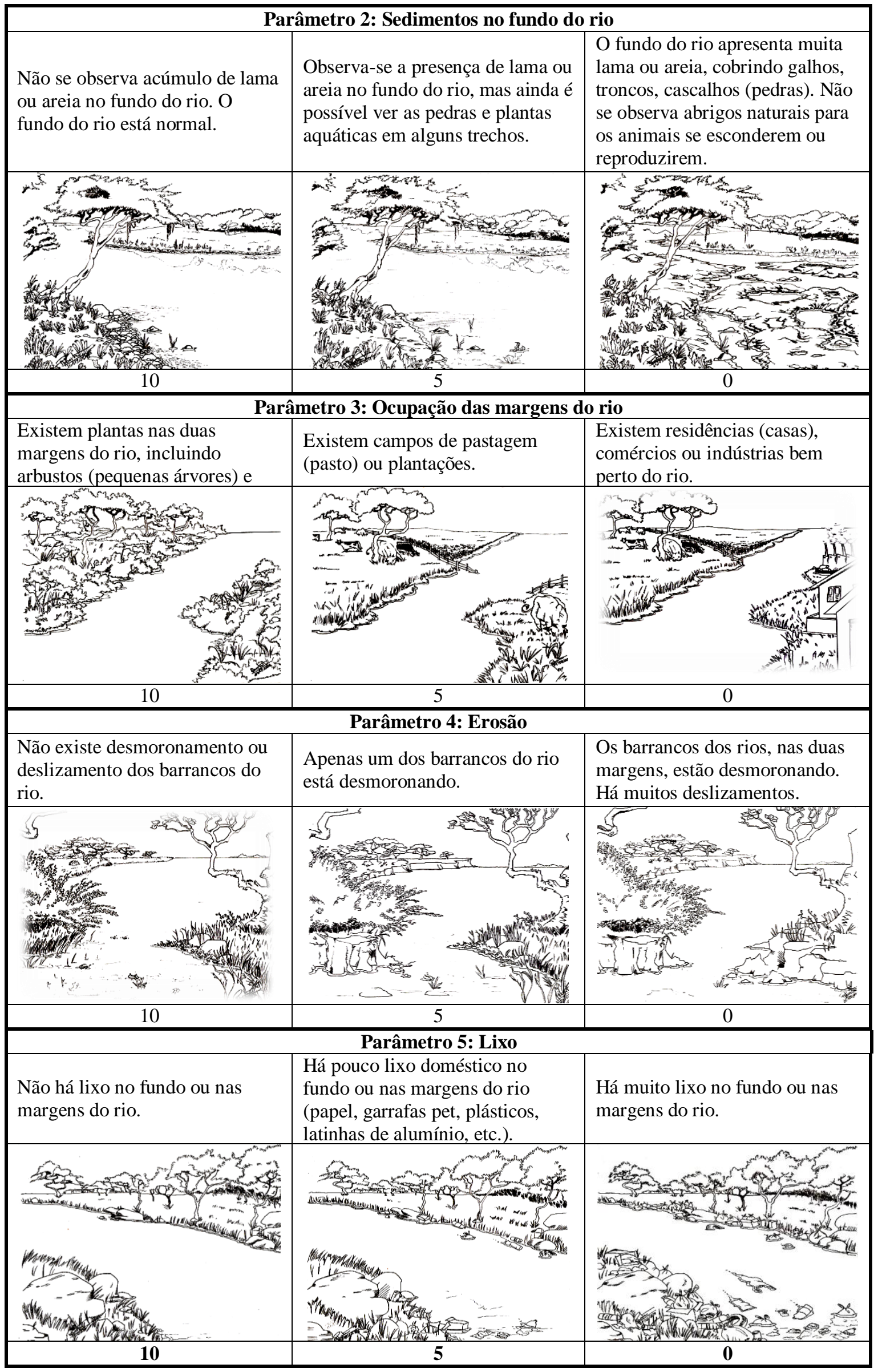


GUIMARÃES, A.; RODRIGUES, A. S. L.; MALAFAIA, G. Adequação de um protocolo de avaliação rápida de rios para ser usado por estudantes do ensino fundamental. Ambi-Agua, Taubaté, v. 7, n. 3, p. 241-260, 2012. (http://dx.doi.org/10.4136/ambi-agua.996)

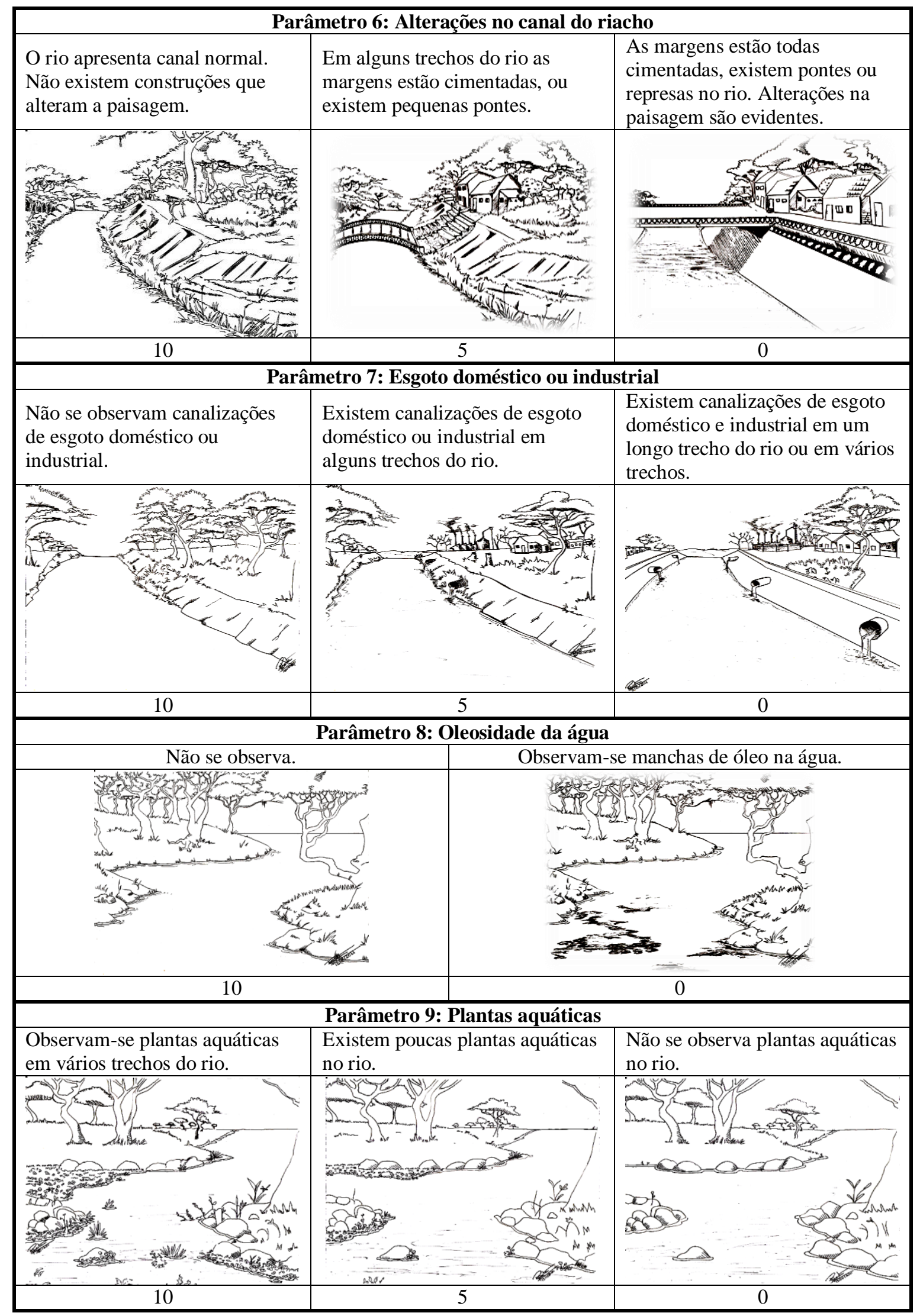


GUIMARÃES, A.; RODRIGUES, A. S. L.; MALAFAIA, G. Adequação de um protocolo de avaliação rápida de rios para ser usado por estudantes do ensino fundamental. Ambi-Agua, Taubaté, v. 7, n. 3, p. 241-260, 2012. (http://dx.doi.org/10.4136/ambi-agua.996)

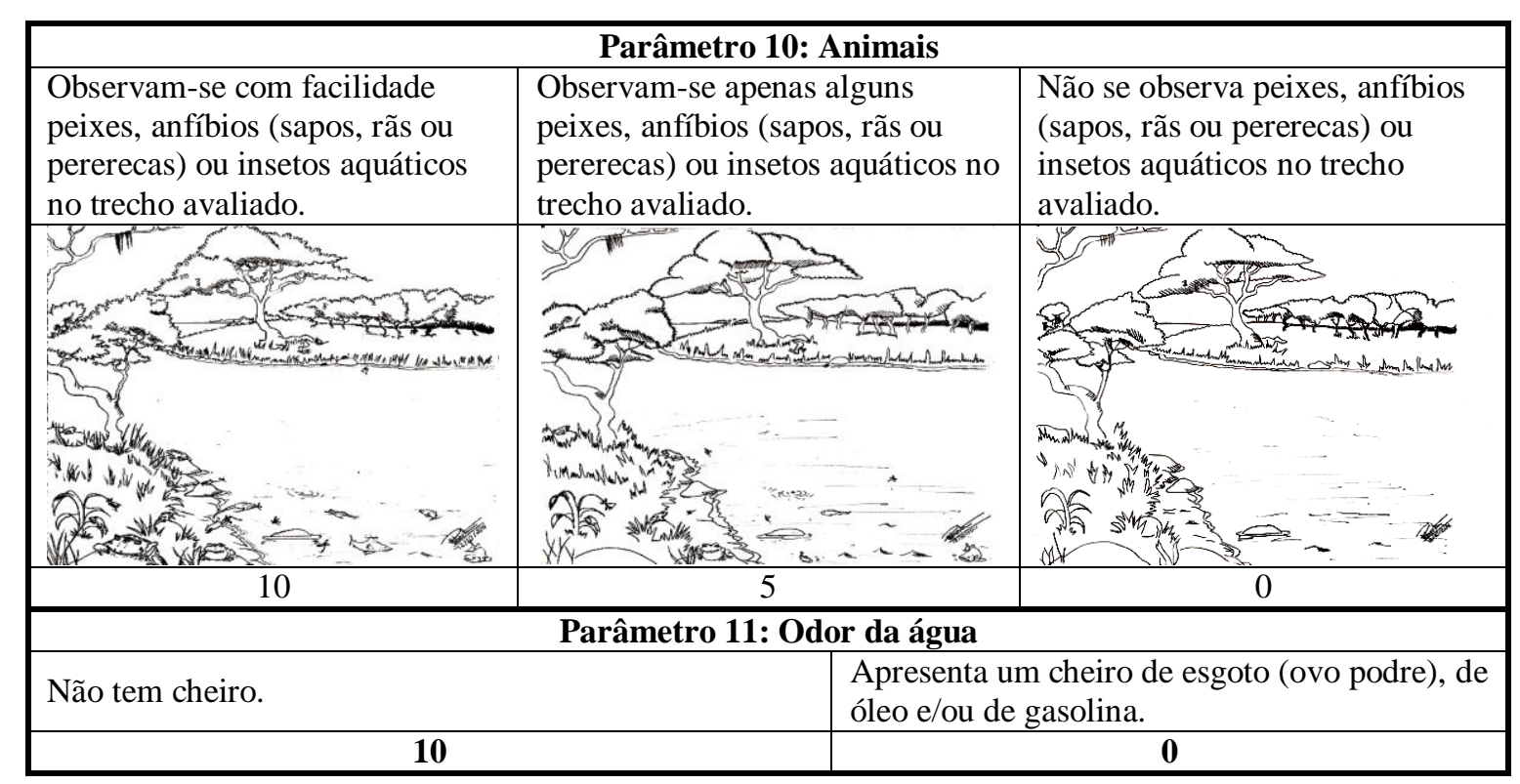

Após o desenvolvimento da parte teórica da oficina de monitoramento ambiental, os alunos foram a campo e aplicaram o PAR adequado. O tempo de aplicação do PAR pelos discentes variou entre 20 e 40 minutos, tempo este considerado relativamente pequeno. Os participantes relataram que o instrumento desenvolvido os aproxima das questões ambientais $(81 \%$ - $n=77)$, que as instruções da oficina de monitoramento ambiental ajudaram na melhor compreensão do instrumento $(75 \%$ - $n=71)$ e que as ilustrações disponíveis em cada parâmetro ajudaram significativamente durante a avaliação em campo, bem como durante a atribuição de notas aos parâmetros $(92 \%$ - $n=87)$. Além disso, $90 \%(n=86)$ dos participantes afirmaram que se sentiram sensibilizados para com as questões ligadas à preservação dos recursos hídricos, 96\% ( $\mathrm{n}=91)$ disseram que a participação na oficina de monitoramento ambiental permitiu a apropriação de conhecimentos sobre o funcionamento dos sistemas fluviais e o mesmo percentual afirmou que o PAR adequado pode ser utilizado por qualquer pessoal previamente treinada. O Quadro 5 mostra alguns comentários emitidos pelos alunos quando do preenchimento do questionário investigativo.

Conforme pode ser observado na Figura 2, os resultados da aplicação do PAR pelos discentes apresentaram variações. Porém, a análise estatística realizada revelou que essas variações não correspondem a diferenças significativas $(p=0,998$, pelo teste de Bartlett e $p=0,985$, pelo teste de Levene). Além disso, os resultados das avaliações realizadas pelos alunos no trecho de rio selecionado foram muito semelhantes aos obtidos em estudo recente também desenvolvido em Ipameri, GO. Este estudo refere-se ao trabalho de Firmino et al. (2011), no qual foi realizado um diagnóstico da integridade ambiental de trechos de rios localizados na cidade de Ipameri, por meio de um PAR (inespecífico ao nível de escolaridade do ensino fundamental). Em ambos os estudos, o mesmo trecho de rio (Figura 3) foi enquadrado numa condição "boa". A média do somatório das pontuações referentes à avaliação do trecho pelos discentes, no presente trabalho, foi de 49,1 (o que corresponde à condição "boa") e no estudo de Firmino et al. (2011) a pontuação média do referido trecho foi de 14,1, o que também corresponde à uma condição "boa", dentro de quatro possíveis categorias estabelecidas. 
GUIMARÃES, A.; RODRIGUES, A. S. L.; MALAFAIA, G. Adequação de um protocolo de avaliação rápida de rios para ser usado por estudantes do ensino fundamental. Ambi-Agua, Taubaté, v. 7, n. 3, p. 241-260, 2012. (http://dx.doi.org/10.4136/ambi-agua.996)

Quadro 5. Comentários emitidos por alguns discentes referentes a algumas questões do questionário aplicado ao final da oficina de monitoramento ambiental.

\begin{tabular}{|c|c|}
\hline Questões & Comentários \\
\hline $\begin{array}{l}\text { Durante a avaliação do rio com o } \\
\text { protocolo, você se sentiu um agente } \\
\text { colaborador na defesa de um rio? }\end{array}$ & $\begin{array}{l}\text { - "Porque às vezes a gente se senti uma pessoa } \\
\text { importante que ajuda o meio ambiente" (aluna, } 8^{\circ} \\
\text { ano). } \\
\text { - "Porque ao avaliarmos o rio percebemos o quanto } \\
\text { poluímos" (aluno, } 9^{\circ} \text { ano). } \\
\text { - "Porque eu posso saber as desvantagens de agir de } \\
\text { forma poluidora" (aluna, } 7^{\circ} \text { ano). }\end{array}$ \\
\hline $\begin{array}{l}\text { As ilustrações disponíveis em cada } \\
\text { parâmetro o ajudaram durante a avaliação } \\
\text { em campo e durante a atribuição de notas } \\
\text { aos parâmetros? }\end{array}$ & $\begin{array}{l}\text { - "Os desenhos facilitaram demais a marcação das } \\
\text { notas" (aluno, } 9^{\circ} \text { ano). } \\
\text { - "Sem a presença de algumas figuras eu não ia } \\
\text { conseguir dar nota ao rio" (aluna, } 7^{\circ} \text { ano). } \\
\text { - "As imagens ajudaram bastante" (aluno, } 9^{\circ} \text { ano). }\end{array}$ \\
\hline $\begin{array}{l}\text { A participação na oficina de } \\
\text { monitoramento ambiental permitiu a } \\
\text { apropriação de conhecimentos sobre o } \\
\text { funcionamento dos sistemas fluviais }\end{array}$ & $\begin{array}{l}\text { - "Aprendi muita coisa interessante com a oficina. Ela } \\
\text { - "A oficina acontecer mais vezes" (aluna, } 9^{\circ} \text { ano). } \\
\text { escola" (aluno, } 8^{\circ} \text { ano). } \\
\text { - "Através da oficina aprendi inúmeros aspectos do } \\
\text { funcionamento dos rios da nossa cidade" (aluno, } 9^{\circ} \\
\text { ano). }\end{array}$ \\
\hline $\begin{array}{l}\text { Você acredita que qualquer pessoa } \\
\text { previamente treinada pode realizar a } \\
\text { avaliação de um rio utilizando-se este } \\
\text { PAR? }\end{array}$ & $\begin{array}{l}\text { - "Qualquer pessoa pode aplicar o protocolo, desde } \\
\text { que ajudada por uma aula antes da aplicação" (aluno, } \\
9^{\circ} \text { ano). } \\
\text { "O protocolo foi muito fácil de utilizar. Acredito que } \\
\text { todos podem aplicar o instrumento em rios da } \\
\text { cidade" (aluna, } 8^{\circ} \text { ano). }\end{array}$ \\
\hline
\end{tabular}

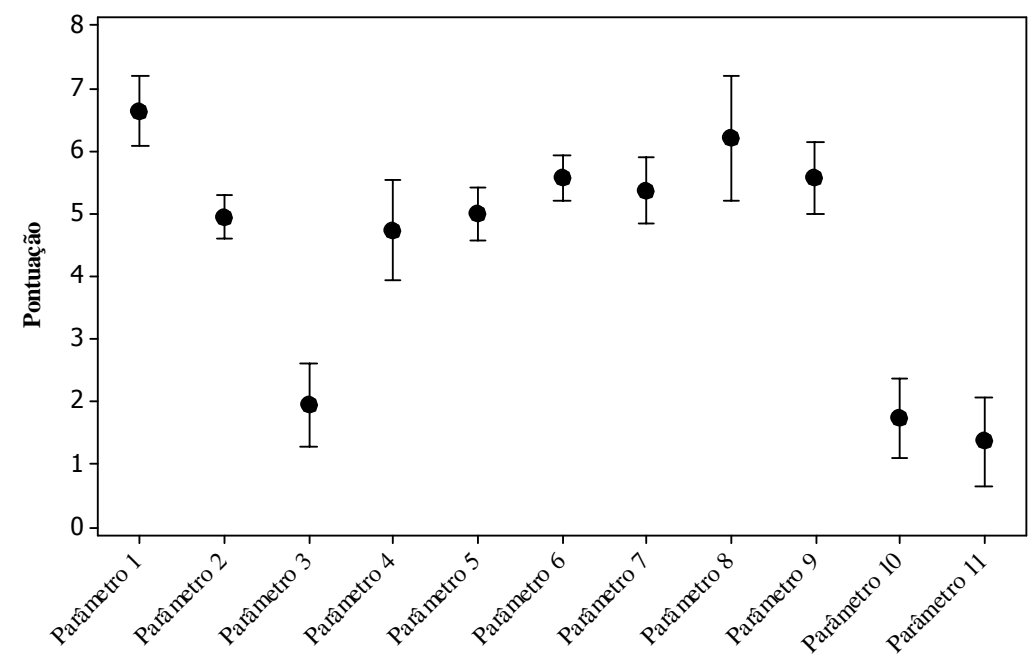

Figura 2. Variação da pontuação atribuída aos parâmetros analisados por 95 voluntários, alunos de ensino fundamental, em um trecho de rio na cidade de Ipameri, GO. Os pontos no gráfico representam a média +/- desvio padrão das pontuações atribuídas a cada parâmetro do protocolo desenvolvido.

Nota: Parâmetro 1: Características do fundo do rio; Parâmetro 2: Sedimentos no fundo do rio; Parâmetro 3: Ocupação das margens do rio; Parâmetro 4: Erosão; Parâmetro 5: Lixo; Parâmetro 6: Alterações no canal do riacho; Parâmetro 7: Esgoto doméstico ou industrial; Parâmetro 8: Oleosidade da água; Parâmetro 9: Plantas aquáticas; Parâmetro 10: Animais; Parâmetro 11: Odor da água. 


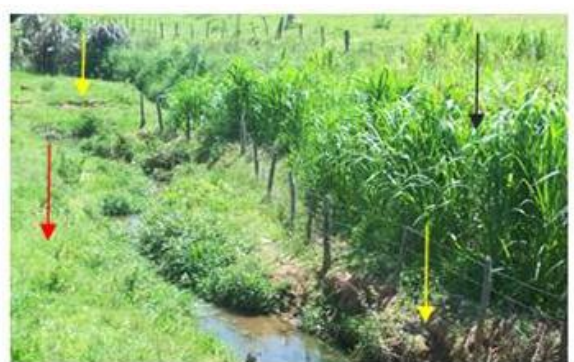

A

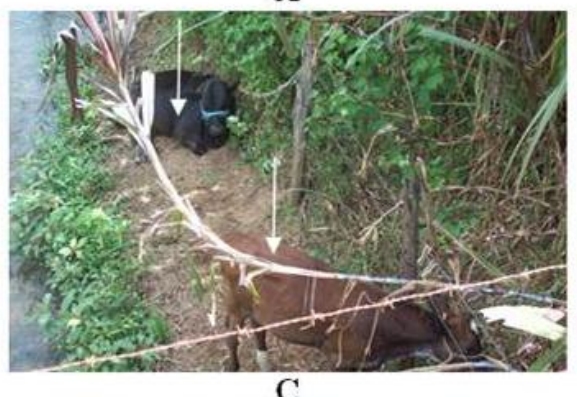

$\mathrm{C}$

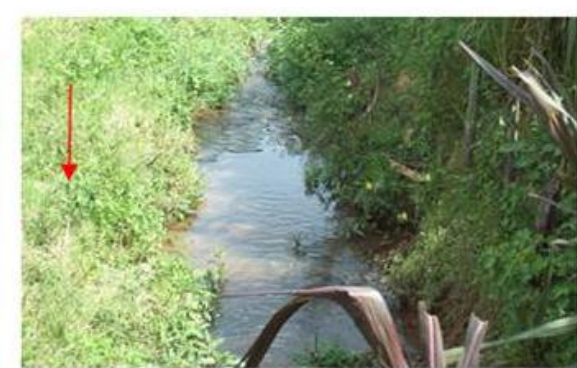

B

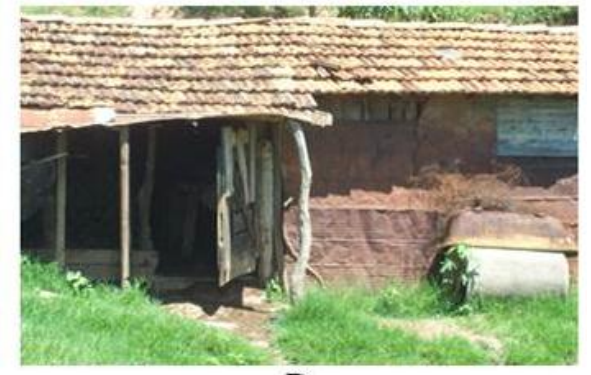

D

Figura 3. Imagens do entorno e do trecho de rio avaliado pelos discentes participantes da oficina de monitoramento ambiental, por meio do protocolo adequado no presente estudo (Ipameri, GO) ${ }^{1,2}$.

Nota: 'Esse trecho corresponde ao ponto 7 - coordenadas $48^{\circ} 09^{\prime} 09^{\prime \prime}$ O $17^{\circ} 42^{\prime} 40^{\prime \prime} \mathrm{S}$.

${ }^{2}$ As setas amarelas indicam processos erosivos em uma das margens do trecho avaliado, as setas vermelhas indicam áreas de pastagem, a seta preta área de cultivo e as setas brancas indicam animais domésticos em uma das margens do trecho.

Ao associar as características do trecho avaliado pelos discentes com as pontuações atribuídas pelos mesmos com base nas características do curso d'água apresentadas no dia da avaliação, também foi possível observar evidências que justificam o enquadramento da condição ambiental do trecho em uma condição "boa". As pontuações medianas atribuídas aos parâmetros 4, 5, 6, 7 e 8 condizem com a condição verificada no local. Para os parâmetros 4,5 e 6 as notas atribuídas não foram tão elevada possivelmente em função de uma das margens do trecho apresentar-se mais impactada que a outra. Processos erosivos na margem direita do trecho (conforme ilustrado na Figura 3A - setas amarelas) podem ser evidenciados, assim como a presença de lixo próximo à residência localizada à margem esquerda do trecho (Figura 3D). Já as alterações no canal foram mais intensas próximas à residência, mas ao longo do trecho as alterações que influenciam o curso normal do rio foram mínimas (o que justifica a nota mediana atribuída ao parâmetro). Já as baixas pontuações atribuídas aos parâmetros 3, 10 e 11 refletem a intensa ocupação das margens do rio com áreas de pastagens, criação de gado (Figura 3A, 3B e 3C - setas vermelhas e brancas) e cultivo (Figura 3A - seta preta), bem como ao odor de esgoto doméstico oriundo da residência localizada próxima ao trecho e à ausência de animais silvestres às margens do curso d'água (justificada pela ocupação humana ou ao período ou época do ano em que a avaliação do trecho foi realizada).

Nesse sentido, os resultados da oficina possibilitam inferir que o PAR adequado mostrase compreensível por parte dos avaliadores (discentes), já que não há variações significativas nas respostas dos avaliadores, bem como capaz de detectar perturbações no curso d'água que são condizentes com as características do local de avaliação.

Cabe ressaltar que apesar de não terem sido significativas estatisticamente, as variações das pontuações atribuídas aos parâmetros 4 ("Erosão") e 8 ("Oleosidade da água") foram as maiores. Tais variações podem ser explicadas possivelmente pela maior dificuldade, por parte 
dos alunos, de entender o que o parâmetro propunha mensurar ou indicar. Dentre os parâmetros que apresentaram maior dificuldade de entendimento no PAR adequado, os parâmetros 4 e 8 foram os mais mencionados pelos discentes (ambos foram mencionados por 66,7\% ( $\mathrm{n}=18)$ dos discentes que afirmaram ter dificuldade de entendimento dos parâmetros $\mathrm{n}=27$ ). Em função disso, a descrição de ambos os parâmetros sofreram modificações de modo a permitir um maior entendimento por parte dos avaliadores. A versão do PAR apresentada neste estudo (Quadro 3) refere-se àquela pós-modificação destes parâmetros em específico. Ainda assim, acredita-se é natural que ocorra variações, principalmente em função do PAR ser um instrumento que alberga certa subjetividade. Para Rodrigues e Castro (2008a), a subjetividade do método pode ser amenizada com maior treinamento do avaliador, com a realização de cursos de capacitação e com o acompanhamento parcial e de suporte de avaliadores mais experientes.

Do ponto de vista da conservação dos recursos hídricos, pode-se dizer que atualmente é indiscutível a importância do monitoramento e avaliação ambiental desses recursos, sobretudo quando se considera que a demanda e a oferta desses está cada vez mais comprometida em função das atividades poluidoras diversas. A grande quantidade de estudos sobre avaliação e monitoramento desses recursos, em diferentes contextos regionais, revela a importância que tem sido dada a essa temática (Farias et al., 2011; Vargas e Ferreira Júnior, 2012; Baldissera et al., 2011; Guedes et al., 2012; Pereira et al., 2012, Firmino et al., 2011; Rodrigues et al., 2012; Bailly et al., 2012). Porém, esses estudos têm focado análises mais técnicas, com destaque para avaliações dos parâmetros físico-químicos e microbiológicos da água, com pouca atenção aos fatores físicos condicionantes da qualidade do ecossistema fluvial, bem como aos aspectos sociais e à inserção da comunidade nessas avaliações.

No presente estudo, propõe-se uma ferramenta que permite a avaliação rápida de riachos de uma forma mais genérica e não apenas ligadas à qualidade físico-química e microbiológica da água, ao mesmo tempo em que oportuniza a inserção de jovens estudantes nessa avaliação. Nesse sentido, pode-se dizer que o instrumento aqui proposto pode contribuir enormemente para com o desenvolvimento da EA envolvendo crianças e a preservação dos recursos fluviais locais.

A utilização do PAR em projetos de EA desenvolvidos em instituições de ensino podem despertar nas crianças a atenção para as condições ambientais do recurso hídrico da localidade. Baseando-se em critérios técnicos (discriminados no próprio PAR, de forma adaptada à linguagem do ensino fundamental), oportunizou-se aos discentes a percepção e identificação de possíveis impactos que podem passar despercebidos no seu dia-a-dia, principalmente devido ao fato do impacto já ter se incorporado à realidade das pessoas e não ser enxergado como um problema ambiental. É possível então, que o PAR, aliado a análises complementares do recurso fluvial em questão, proporcione em consórcio com o desenvolvimento de atividades teórico/reflexivas o desenvolvimento de uma compreensão integrada dos recursos fluviais (incluindo aspectos ecológicos); o fortalecimento de uma consciência crítica sobre a problemática ambiental, bem como o incentivo à participação individual e coletiva na preservação do equilíbrio dos recursos hídricos, entendendo-se a defesa da qualidade ambiental como um valor inseparável do exercício da cidadania.

Estudos como os desenvolvidos por Guimarães et al. (2006) (comentado inicialmente), Bergmann e Pedrozo (2008) e por França et al. (2010), por exemplo, constituem experiências bem sucedidas ligadas à utilização de PAR por estudantes em projetos de EA, apesar de nenhum deles ter adequado um PAR especificamente para uso por estudantes do ensino fundamental. No estudo de Bergmann e Pedrozo (2008), em duas escolas públicas do município de Giruá, RS, com ênfase na sub-bacia do rio Santo Cristo, ao aplicarem um PAR durante as atividades de campo, os alunos do ensino médio puderam não apenas ter contato com uma ferramenta de avaliação ambiental, mas identificar e aprender sobre como evitar ou 
minimizar problemas ambientais da sub-bacia hidrográfica local. França et al. (2010), por meio de atividades envolvendo apresentação de vídeo, exposição interativa, jogos lúdicos, visitas a uma nascente (fonte de abastecimento de água do município) do Refúgio de Vida Silvestre (RVS) Mata do Junto (Capela, SE) e aplicação de um PAR, trabalharam EA de modo a promover a conscientização de jovens estudantes sobre a importância de seu papel na preservação dos recursos fluviais.

\section{CONCLUSÕES}

Os resultados deste estudo permitem concluir que o PAR adequado apresenta-se como ferramenta viável e útil no desenvolvimento da EA no nível fundamental da educação. Em adição, tal ferramenta foi capaz de permitir a observação, sensibilização e apropriação de conceitos referentes ao funcionamento e à preservação dos recursos fluviais locais, contribuindo significativamente com o desenvolvimento da EA no nível básico da educação.

Salienta-se que o PAR proposto neste estudo mostra-se viável para a utilização em instituições de ensino (públicas ou particulares) em projetos/programas de EA, bem como por organizações-não-governamentais relacionadas à preservação ambiental.

\section{AGRADECIMENTOS}

Os autores agradecem ao IF Goiano - Campus Urutaí pelo financiamento do projeto. Guimarães A. agradece ao CNPq pela concessão da bolsa de iniciação Científica (vigência: 2011-2012) e Rodrigues A.S.L. agradece ao IF Goiano pela concessão da bolsa produtividade (vigência: 2012)..

\section{REFERÊNCIAS}

BAILLY, D.; FERNANDES, C. A.; SILVA, V. F. B.; KASHIWAQUI, E. A. L.; DAMÁSIO, J. F.; WOLF, M. J. et al. Diagnóstico ambiental e impactos sobre a vegetação ciliar da microbacia do córrego da Ponte, Área de proteção ambiental do rio Iguatemi, MS. Revista em Agronegócios e Meio Ambiente, Maringá, v. 5, n. 2, p. 409-427, 2012.

BALDISSERA, I. T.; ZAMPIERI, S. L.; BAMPI, D. B. Monitoramento da qualidade da água na microbacia Tarumanzinho em Águas Frias, SC, Brasil. Revista de Ciências Ambientais, Canoas, v. 5, n. 2, p. 5-14, 2011.

BARBOUR, M.T.; GERRISTSEN, J.; SNYDER, B.; STRIBLING, J. Rapid bioassessment protocols for use in streams and wade able rivers: periphyton, benthic macroinvertebrates and fish. 2. ed. Washington: EPA 1999. 339p.

BERGMANN M.; PEDROZO C. S. Explorando a bacia hidrográfica na escola: contribuições à educação ambiental. Revista Ciência \& Educação, Bauru, v. 14, n. 3, p. 537-553. 2008. http://dx.doi.org/10.1590/S1516-73132008000300011

BIZERRIL, M. X. A.; FARIA, D. S. A escola e a conservação do cerrado: uma análise no ensino fundamental do Distrito Federal. Revista Eletrônica do Mestrado em Educação Ambiental, Rio Grande, v. 10, p. 19-31, 2003.

BROWN, M. B.; FORSYTHE, A. B. Robust tests for the equality of variances. Journal of the American Statistical Association, Alexandria, v. 69, n. 346, p. 1-9, 1974. http://dx.doi.org/10.1080/01621459.1974.10482955 
CALLISTO, M.; RIBEIRO, A.; SANTANA, V. B. Integração, treinamento e formação de pós-graduandos para a conservação de riachos de cabeceira. In: ENCONTRO DE RECURSOS HÍDRICOS EM SERGIPE, 3., 2010, Aracajú. Resumos expandidos... Aracajú: Embrapa Tabuleiros Costeiros, 2010. Disponível em: <http://www.cpatc. embrapa.br/publicacoes_2010/anais3_enrehse>. Acesso em: 3 jul. 2012.

CALliSTO, M.; FERREIRA, W.; MORENO, P.; GOULART, M. D. C.; PETRUCIO, M. Aplicação de um protocolo de avaliação rápida da diversidade de habitats em atividades de ensino e pesquisa (MG-RJ). Acta Limnologica Brasiliense, Sorocaba, v. 14, n. 1, p. 91-98, 2002.

CARVALHO, E. M. Estudo da utilização de um protocolo de avaliação rápida da diversidade de habitats em atividade complementar de ensino (UEMS - Dourados). In: ENCONTRO DE ENSINO DE GRADUAÇÃO, 1., 2010, Dourados. Anais... Dourados: UEMS, 2010.

DILLENBURG, A. K. A importância do monitoramento ambiental na avaliação da qualidade de um rio - estudo de caso - Mercedes, PR. Revista Urutágua - Revista Acadêmica Multidisciplinar, Maringá, n. 12, p. 1-10, 2007.

FARIAS, M. S. S.; DANTAS NETO, J.; LIMA, V. L. A. Monitoramento da qualidade da água na bacia hidrográfica do Rio Cabelo: parâmetros físico-químicos. GEPROS Gestão da Produção, Operações e Sistemas, Bauru, v. 6, n. 1, p. 161-170, 2011.

FRANÇA, J.; ANDRADE, C.; FONTENELE, A. C.; SANTOS, R. C.; RIBEIRO, A.; CALLISTO, M. Atividades de educação ambiental com comunidades do entorno do RVS Mata do Junco, Capela, SE. In: ENCONTRO DE RECURSOS HÍDRICOS EM SERGIPE, 3., 2010, Aracaju. Resumos expandidos... Aracajú: Embrapa Tabuleiros Costeiros, 2010. p. 1-4.

FIRMINO, P. F.; MALAFAIA, G.; RODRIGUES, A. S. L. Diagnóstico da integridade ambiental de trechos de rios localizados no município de Ipameri, Sudeste do Estado de Goiás, através de um protocolo de avaliação rápida. Brazilian Journal of Aquatic Science and Technology, Itajaí, v. 15, n. 2, p. 1-12, 2011.

GUEDES, H. A. S.; SILVA, D. D.; ELESBON, A. A. A.; RIBEIRO, C. B. M.; MATOS, A. T.; SOARES, J. H. P. Aplicação da análise estatística multivariada no estudo da qualidade da água do Rio Pomba, MG. Revista Brasileira de Engenharia Agrícola e Ambiental, Campina Grande, v. 16, n. 5, p. 558-563, 2012. http://dx.doi.org/10.1590/S1415-43662012000500012

GUIMARÃES, A. Q. et al. Uso de ferramentas alternativas para auxiliar saídas de campo e construção de valores conservacionistas. In: CONGRESSO IBERO-AMERICANO DE EDUCAÇÃO AMBIENTAL, 5., 2006. Joinville. Anais... Brasília: MMA, 2006.

INSTITUTO BRASILEIRO DE GEOGRAFIA E ESTATÍSTICA -IBGE. Censo 2010. Disponível em: <http://www.ibge.gov.br/home/estatistica/populacao/censo2010/ calendario.shtm>. Acesso em: 10 out. 2012.

IPAMERI. Prefeitura Municipal. Informações gerais sobre o município de Ipameri. Disponível em: <http://www.ipameri.go.gov.br/site/12/html/informacoes-gerais.html>. Acesso em: 16 de abr. 2010.

KRUPEK, R. A. Análise comparativa entre duas bacias hidrográficas utilizando um protocolo de avaliação rápida da diversidade de habitats. Ambiência, Guarapuava, v. 6, n. 1, p. 147-158, 2010. 
LOBO, E. A.; VOOS, J. G.; ABREU JÚNIOR, E. F. Utilização de um protocolo de avaliação rápida de impacto ambiental em sistemas lóticos do Sul do Brasil. Caderno de Pesquisa, Série Biologia, Santa Cruz, v. 23, n. 1, p. 18-33, 2011.

MINATTI-FERREIRA, D. D.; BEAUMORD, A. C. Avaliação rápida de integridade ambiental das sub-bacias do rio Itajaí-Mirim no Município de Brusque, SC. Revista Saúde \& Ambiente, Joinville, v. 5, n. 2, p. 21-27, 2004.

MINATTI-FERREIRA, D. D.; BEAUMORD, A. C. Adequação de um protocolo de avaliação rápida de integridade ambiental para ecossistemas de rios e riachos: aspectos físicos. Revista Saúde e Ambiente, Joinville, v. 7, n. 1, p. 39-47, 2006.

PADOVESI-FONSECA, C.; CORRÊA, A. C. G.; LEITE, G. F. M.; JOVELI, J. C.; COSTA, L. S.; PEREIRA, S. T. Diagnóstico da sub-bacia do ribeirão Mestre d'Armas por meio de dois métodos de avaliação ambiental rápida, Distrito Federal, Brasil Central. Revista Ambiente \& Água, Taubaté, v. 5, n. 1, p. 43-56, 2010. http://dx.doi.org/10.4136/1980993X

PALHARES, K.; MAYRINK, N.; MORENO, P.; GOULART, M.; MORETTI, M.; FERREIRA, W. Bioindicadores de qualidade de água: a educação ambiental como uma ferramenta de união UFMG-escolas. In: SIMPÓSIO DE ECOSSISTEMAS BRASILEIROS, 5., 2000, Vitória. Anais... São Paulo: ACIESP, 2000. V. 1. p. 182189.

PEREIRA, P. S.; FERNANDES, L. A. C.; OLIVEIRA, J. L. M.; BAPTISTA, D. F. Avaliação da integridade ecológica de rios em áreas do zoneamento ecológico econômico do complexo hidrográfico Guapiaçu-Macacu, RJ, Brasil. Revista Ambiente \& Água, Taubaté, v. 7, n. 1, p. 157-168, 2012. http://dx.doi.org/10.4136/ambi-agua.762

PIMENTA, S. M.; PENA, A. P.; GOMES, P. S. Aplicação de métodos físicos, químicos e biológicos na avaliação da qualidade das águas em áreas de aproveitamento hidroelétrico da bacia do rio São Tomás, município de Rio Verde - Goiás. Sociedade \& Natureza, Uberlândia, v. 21, n. 3, p. 393-412, 2009. http://dx.doi.org/10.1590/S198245132009000300013

PLAFKIN, J. L.; BARBOUR, M. T.; PORTER, K. D.; GROSS, S. K.; HUGHES, R. M. Rapid bioassessment protocols for use in streams and rivers: benthic macroinvertebrates and fish. Washington: EPA 440-4-89-001, 1989. 339 p.

PREFEITURA MUNICIPAL DE IPAMERI-GO (PMI). Informações gerais sobre o município de Ipameri. Disponível em: http://www.ipameri.go.gov.br/site/12/html/ informacoes-gerais.html. Acesso em: 16 de abr. 2010.

RODRIGUES, A. S. L.; CASTRO, P. T. A. Adaptation of a rapid assessment protocol for rivers on rocky meadows. Acta Limnologica Brasiliense, Sorocaba, v. 20, n. 4, p. 291$303,2008 b$.

RODRIGUES, A. S. L.; CASTRO, P. T. A. Protocolos de avaliação rápida: instrumentos complementares no monitoramento dos recursos hídricos. Revista Brasileira de Recursos Hídricos, Porto Alegre, v. 13, n. 1, p. 161-170, 2008a.

RODRIGUES, A. S. L.; CASTRO, P. T. A.; MALAFAIA, G. Utilização dos protocolos de avaliação rápida de rios como instrumentos complementares na gestão de bacias hidrográficas envolvendo aspectos da geomorfologia fluvial: uma breve discussão. Enciclopédia Biosfera, Goiânia, v. 6, n. 11, p. 1- 9, 2010. 
RODRIGUES, A. S. L.; MALAFAIA, G.; CASTRO, P. T. A. Avaliação ambiental de trechos de rios na região de Ouro Preto-MG através de um protocolo de avaliação rápida. Revista de Estudos Ambientais, Blumenau, v. 10, n. 1, p. 74-83, 2008.

RODRIGUES, A. S. L.; MALAFAIA, G.; COSTA, A. T.; NALINI-JÚNIOR, H. A. Adequação e avaliação da aplicabilidade de um Protocolo de Avaliação Rápida na bacia do rio Gualaxo do Norte, Leste-Sudeste do Quadrilátero Ferrífero, MG, Brasil. Revista Ambiente \& Água, Taubaté, v. 7, n. 2, p. 231-244, 2012. http://dx.doi.org/10.4136/ambi-agua.872

SNEDECOR, G. W.; COCHRAN, W. G. Statistical methods. 8. ed. Iowa: State University Press, 1989.

VARGAS, J. R. A.; FERREIRA JÚNIOR, P.D. Aplicação de um protocolo de avaliação rápida na caracterização da qualidade ambiental de duas microbacias do rio Guandu, Afonso Cláudio, ES. Revista Brasileira de Recursos Hídricos, Porto Alegre, v. 17, n. 1, p. 161-168, 2012.

XAVIER, A. L.; TEIXEIRA, D. A. Diagnóstico das nascentes da sub-bacia hidrográfica do rio São João em Itaúna, MG. In: CONGRESSO DE ECOLOGIA DO BRASIL, 7. 2007, Caxambu. Anais... Caxambu: SEB, 2007. p. 1-2. 